\title{
Continuous-Flow Production of Isosorbide from Aqueous-Cellulosic Derivable Feed over Sustainable Heterogeneous Catalysts
}

\author{
Francesco Brandi, ${ }^{\S}$ Ibrahim Khalil, Markus Antonietti, and Majd Al-Naji*, ${ }^{\S}$
}

Cite This: ACS Sustainable Chem. Eng. 2021, 9, 927-935

Read Online

ABSTRACT: Continuous-flow sorbitol dehydration in liquid water was performed on $\beta$ zeolite $(\mathrm{Si} / \mathrm{Al}$ molar ratio $=75)$ with conversion of 94 and $83 \mathrm{~mol} \%$ isosorbide yield. This efficiency is due to the three-dimension pore architecture, high specific surface area $\left(520 \mathrm{~m}^{2} \mathrm{~g}^{-1}\right)$, and Brønsted acid sites of $69 \mu \mathrm{mol} \mathrm{g} \mathrm{g}^{-1}$. The pore size of $\beta$ zeolite $\left(6.6 \times 6.7 \AA^{2}\right)$ is slightly larger than the cross section of sorbitol and isosorbide and enables an efficient diffusion of the reactant and product to/from the pores. Operation in continuous flow allows rapid dehydration of sorbitol to 1,4sorbitan, after which the latter got converted to isosorbide. The high yield of isosorbide is attributed to the continuous removal of the formed products from the catalyst surface. Finally, direct isosorbide production from aqueous glucose solution via hydrogenation on $\mathrm{Ni}$ catalyst supported on nitrogen-doped carbon, followed by dehydration of the formed sorbitol to isosorbide, was pioneered.

KEYWORDS: lignocellulosic biomass, continuous flow, sorbitol, isosorbide, zeolite

\section{INTRODUCTION}

Lignocellulosic biomass is presumably one of the most important renewable sources on which the transition toward more sustainable chemical production could be based. ${ }^{1-3}$ Sugars form about $70-80 \%$ of lignocellulosic biomass, which can be further valorized to biobased chemicals for polymers, pharmaceuticals, cosmetics, and food industries. ${ }^{4-9}$ Among these biobased chemicals, glucose is an illustrative case and can be selectively converted to sorbitol (9000 $\left.\mathrm{t} \mathrm{year}^{-1}\right)$ via catalytic reduction. ${ }^{10-12}$ Sorbitol is one of the top "12" promising building blocks according to the United State Department of Energy (DOE) ${ }^{13}$ because it is directly used but also can be further converted to high-value biobased building blocks, e.g., isosorbide and 1,4-sorbitan. ${ }^{14-17}$ Our current focus molecule, isosorbide, possesses its importance from its exponentially growing market (expected to be US $\$ 324.6$ million at the end of 2020), ${ }^{18}$ as well as it is involved in the synthesis of a wide range of green and sustainable final products such as polymers, cosmetics, pharmaceuticals, and solvents. ${ }^{19-27}$ For instance, POLYSORB, ${ }^{28}$ DURABIO, ${ }^{29}$ and PLANEXT ${ }^{30}$ are commercialized isosorbide-based polycarbonates with improved properties with respect to both poly(methyl methacrylate) and bisphenol-A polycarbonate. ${ }^{31}$ As packaging for hot beverages, isosorbide can be polycondensed into poly(ethylene terephthalate) (PET) or polyesters of furan dicarboxylic acid. $^{21,32}$ In addition, it is used for the synthesis of dimethyl isosorbide, an alternative green solvent used also in cosmetics due to its low toxicity and high boiling point $(509 \mathrm{~K}) \cdot{ }^{17,33}$ In medicine, isosorbide and its derivatives (mono and dinitrate) are widely employed, especially as vasodilators in cardiologic disease treatments. ${ }^{34,35}$ Industrially, isosorbide is produced with a yield of $77 \mathrm{~mol} \%$ by homogeneous dehydration of sorbitol by $\mathrm{H}_{2} \mathrm{SO}_{4}$ at $403 \mathrm{~K}^{36-38}$ In general, this process offers high isosorbide yield, but it is neither economically efficient nor sustainable due to the intrinsic drawbacks of using homogeneous catalysts. ${ }^{39,40}$ Aiming at heterogeneous alternatives, several solid acid catalysts, i.e., zeolites, mixed oxides, and resins, have been proposed for isosorbide production from sorbitol. ${ }^{15,41-54}$ These trials used a molten bulk phase in small quantities (the solid phase consists of sorbitol and catalyst), i.e., they cannot be largely scaled. ${ }^{55,56}$ Of these catalysts, zeolite was found to be the optimum choice for dehydration of sorbitol to isosorbide, and $\beta$ zeolite showed the highest catalytic performance (isosorbide yield $\sim 80 \mathrm{~mol} \%$ ), as it possesses suitable textural properties, i.e., a pore size distribution of 5-7 $\AA$ and acid-side density above $300 \mu \mathrm{mol}$ $\mathrm{g}^{-1} \cdot 57,58$ Also, catalyst-free sorbitol dehydration to isosorbide in compressed water $(590 \mathrm{~K})$ under $10 \mathrm{MPa}$ of $\mathrm{CO}_{2}$ was reported, with a yield of isosorbide of $57 \% .{ }^{59}$ Uniquely, the Sels group showed that isosorbide $(>60 \mathrm{~mol} \%)$ can be straightforwardly produced from cellulose using two different

Received: November 8, 2020

Revised: December 15, 2020

Published: December 31, 2020 
Scheme 1. Presented Synthesis of Isosorbide by Hydrogenation of Glucose to Sorbitol over 35Ni/NDC, Followed by Sorbitol Dehydration to 1,4-Sorbitan and Finally to Isosorbide over $\beta$ Zeolite

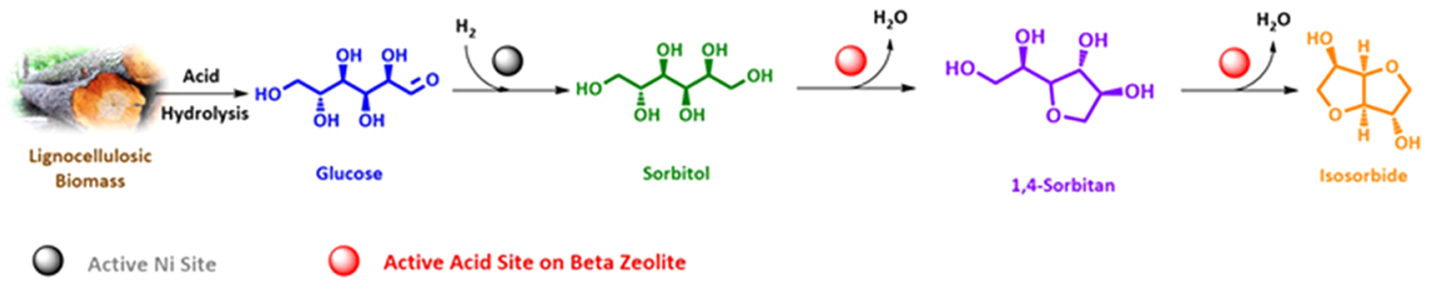

catalysts (heteropoly acids for the dehydration reactions and $\mathrm{Ru}$ on carbon for the hydrogenation reaction) at $503 \mathrm{~K}$ and under $5 \mathrm{MPa}$ of $\mathrm{H}_{2}{ }^{60}$ Similarly, the direct complete conversion of aqueous glucose solution to isosorbide (yield $=79 \mathrm{~mol} \%$ ) was reported using $\mathrm{Ru}$ /Dowex at $463 \mathrm{~K}$ after $24 \mathrm{~h}$ in a batch system. $^{18}$

Seeking for more sustainable, efficient, and economically competitive green processes, the use of heterogeneous catalysts in continuous-flow systems presents advantages over batch counterparts, such as minimization of downstream costs, higher thermal efficiency, and less hazardous nature. ${ }^{61-67}$ Moreover, flow regimes allow novel chemical transformations not achievable in batch. ${ }^{61,63}$ To date, isosorbide synthesis in flow systems has been reported using only water steam, i.e., gas-phase reactions. ${ }^{50,68-70}$ The group of Huang tested various solid acids such as sulfated copper oxide, ${ }^{69}$ metal phosphate, ${ }^{68}$ supported tungstophosphoric acid, ${ }^{50}$ and modified tantalum oxide by phosphoric acid in the gas-phase dehydration of sorbitol to isosorbide. ${ }^{70}$ The highest isosorbide yield using these solid acids in the gas-phase reaction was $68 \mathrm{~mol} \%$ at 473 $\mathrm{K} .{ }^{69}$ However, all of these above-mentioned approaches rely on the usage of the gas-phase reaction using $\mathrm{N}_{2}$ as a carrier and inert gas. Also, $\mathrm{Xi}$ et al. ${ }^{71}$ reported a sequential process for isosorbide production from cellulose, composed by cellulose depolymerization/hydrogenation toward sorbitol using $\mathrm{Ru} /$ $\mathrm{NbOPO}_{4}-\mathrm{pH}_{2}$ in the batch system. In a separated second step, steam of the formed sorbitol was flown over $\mathrm{NbOPO}_{4}-\mathrm{pH}_{2}$ for isosorbide production, with an isosorbide yield of $57 \mathrm{~mol} \%{ }^{71}$ When compared to water in the liquid phase, the use of vaporphase reaction presents additional costs such as the gas supply and gas-liquid separation. In these terms, we found surprisingly that isosorbide synthesis from sorbitol in the liquid aqueous phase has not been reported yet.

Given the importance of such a sustainable synthesis of isosorbide from sorbitol, we developed an efficient prototypescale production of isosorbide from sorbitol at $503 \mathrm{~K}$ using $\beta$ zeolite in liquid water (Scheme 1). Furthermore, we also report on the integrated process to isosorbide starting from aqueous liquid glucose solution in dual tubular reactors. This process includes first-step aqueous-phase glucose hydrogenation to sorbitol over $\mathrm{Ni}$ catalyst-supported nitrogen-doped carbon (NDC) aiming to replace Raney nickel, followed by dehydration of the formed sorbitol to 1,4-sorbitan and subsequently to isosorbide over $\beta$ zeolite (Scheme 1), all without cleaning or isolating any of the intermediates.

\section{EXPERIMENTAL SECTION}

Materials. $\mathrm{H}$-form $\beta(12.5)$ in the powder form and $\mathrm{H}$-form $\beta(75)$ in the pellet form were supplied by Clariant, whereas $\mathrm{H}$-form $\beta(150)$ in the powder form was obtained from Zeolyst. All $\beta$ zeolites that have been used in this manuscript are coded as follows: $\beta(\mathrm{Si} / \mathrm{Al}$ molar ratio). D-Sorbitol (99\%), isosorbide (98\%), and hydrochloric acid (1.0
M) were purchased from Merck. 1,2,6-Hexanetriol (96\%), dianhydroD-glucitol, sulfuric acid (95-97\%), D-glucose anhydrous (>99.5\%), and L-iditol $(\geq 98 \%)$ were obtained from Sigma-Aldrich. 1,4-Sorbitan (98\%), 2,5-mannitan (98\%), and 2,5-anhydro-D-gluctiol (98\%) were purchased from BIOZOL Diagnostica Vertrieb GmbH. 1,5-AnhydroD-sorbitol (97\%) has been supplied by Acros Organics. Commercial semolina (type durum wheat) was purchased from Divella. Urea and nickel nitrate hexahydrate (>99\%) were supplied from Carl Roth. Zinc oxide nanoparticles $(d=20 \mathrm{~nm})$ were provided by Nanostructured and Amorphous Inc. The $\mathrm{H}_{2}$ (99.999\%) and forming gas (95/5 T50 MFI) cylinders were purchased from Westfalen AG.

Catalyst Preparation. All zeolites were used without any further chemical modification. Prior to the reaction, the zeolites in powder form were pressed up to $10 \mathrm{t}$ using a hydraulic press (CARVER $3851 \mathrm{CE}$ ). Afterward, the zeolite has been crushed and sieved in the range $250-500 \mu \mathrm{m}$ to ensure a homogeneous flow of the reactant through the catalyst bed during the experiment, as well as to avoid the pressure drop and clogging of the system. The $35 \mathrm{wt} \% \mathrm{Ni}$ deposited on nitrogen-doped carbon $(35 \mathrm{Ni} / \mathrm{NDC})$ has been synthesized following the "kitchen lab" synthesis previously reported by our group without any change in the procedure. ${ }^{11}$

Catalyst Characterization. The fresh catalysts were characterized using inductively coupled plasma optical emission spectroscopy (ICP$\mathrm{OES}$ ), $\mathrm{N}_{2}$ physisorption, powder X-ray diffraction (XRD), scanning electron microscopy (SEM), and pyridine adsorption followed by infrared spectroscopy (Pyr-IR). The spent catalysts were characterized by thermogravimetric analysis (TGA), $\mathrm{N}_{2}$ sorption, and XRD. A detailed description of the applied characterization procedures is reported in the Supporting Information (SI).

Continuous-Flow Setup. The sorbitol dehydration to isosorbide experiments was conducted in a homemade continuous-flow fixed bed reactor in an aqueous liquid phase, similar to our previously described system (Figure S1 in the SI). ${ }^{72}$ This system consists of a (A) highperformance liquid chromatography (HPLC) pump equipped with a pressure sensor (Knauer Azura P 4.1S series), (B) a two-side-opened heating unit equipped with a heat controller (model \# 4848 from the Parr Instrument Company), and (C) a sampling unit equipped with proportional relief valves as a pressure regulator (Swagelok SSRL4M8F8-EP), $c f$. Figures S1-S3 in the SI. To ensure efficient heating, an aluminum cylinder with three holes has been placed inside the heating unit from Parr Instrument Company, i.e., a preheating unit for the reactant before it comes in contact with the catalyst, a hole for the thermocouple (model \# A472E5 Parr Instrument Company), and a hole for the reactor (Figure S2 in the SI). The main investigations have been made using a stainless steel tubular reactor (inner diameter $=4.6 \mathrm{~mm}$, outer diameter $=6.5 \mathrm{~mm}$, length $=250 \mathrm{~mm}$ ), while the scale-up experiment, as well as the integrated process for isosorbide production from glucose, has been conducted with a bigger stainless steel reactor (inner diameter $=21 \mathrm{~mm}$, outer diameter $=25 \mathrm{~mm}$, length $=280 \mathrm{~mm}$ ), viz., in Figure S3 in the SI.

To conduct the integrated process for isosorbide production from glucose, two fixed bed reactors have been coupled by combining the previous setup with a hydrogenation setup, similar to the one previously reported by our group. ${ }^{11}$ From the above-described setup, the HPLC pump (A) has been connected to a (B) mass-flow controller for $\mathrm{H}_{2}$ (Brooks Instruments, model SLA5850SC1AF1B2A1) through a (C) " $\mathrm{T}$ " union for $\mathrm{H}_{2}$-reactant mixing (Swagelok SS400-30) before reaching the preheating unit and then to (D1 and D2) 
the coupled two double two-side-opened heating units equipped with independent heat control and (E) a sampling unit (Figure S4 in the SI).

Catalytic Experiments. In a typical experiment of isosorbide production from sorbitol, an aqueous solution of sorbitol $\left(c_{\text {sorbitol }}=\right.$ $0.05 \mathrm{M})$ was fed with the HPLC pump at $0.3 \mathrm{~cm}^{3} \mathrm{~min}^{-1}$ and introduced into the preheating unit to the fixed bed reactor consisting of $2.5 \mathrm{~g}$ of zeolite fixed between two layers of quartz wool (30 g of $\beta(75)$ was used for the experiment in prototype tubular reactor scale). The temperature and pressure were kept constant at room conditions ( $298 \mathrm{~K}$ and atmospheric pressure) for $15 \mathrm{~min}$. Afterward, the system was pressurized to $4.0 \mathrm{MPa}$ to ensure that the presence of the reactant solution in the liquid phase, and the temperature was increased to 503 K. Samples $\left(2.0 \mathrm{~cm}^{3}\right)$ were collected once the steady state was reached, after $c a .30 \mathrm{~min}$ ( $1.5 \mathrm{~h}$ on prototype scale).

In the case of the integrated process, an aqueous solution of glucose $\left(c_{\text {glucose }}=0.05 \mathrm{M}\right)$ was fed with the HPLC pump at $0.7 \mathrm{~cm}^{3}$ $\mathrm{min}^{-1}$ and mixed with an excess of $\mathrm{H}_{2}\left(25 \mathrm{~cm}^{3} \mathrm{~min}^{-1}\right.$ at a pressure of 4.0 MPa) and introduced into the two consecutive tubular reactors (Figure S4 in the SI), the first one set to a temperature of $423 \mathrm{~K}$ and the second at a temperature of $503 \mathrm{~K}$. In this experiment, catalyst masses of $10 \mathrm{~g}$ of $35 \mathrm{Ni} / \mathrm{NDC}$ (the first tubular reactor for hydrogenation of glucose to sorbitol) and $30 \mathrm{~g}$ of $\beta(75)$ at the second tubular reactor (for dehydration of the formed sorbitol from the first reaction to isosorbide) were used. Similar to the abovementioned investigation (dehydration of sorbitol to isosorbide), the system was kept at room conditions for $15 \mathrm{~min}$ and then set to the targeted pressure and temperatures. Samples were collected once both systems reached the steady state, i.e., after ca. $3 \mathrm{~h}$. Qualitative and quantitative analyses of the reactants and products were performed using HPLC/MS and HPLC, respectively. The HPLC chromatograms used for quantification, which have been recorded using a refractive index detector (RID), are shown in Figure S5 in the SI. Detailed information about the reactant and product quantification, as well as the calculation of the turnover frequency (TOF), can be found in the SI.

The batch experiment was conducted in a stainless steel autoclave equipped with PTFE liners from Berghof (model BR-100). The batch catalytic experiments were performed at $503 \mathrm{~K}$ using $30 \mathrm{~cm}^{3}$ of aqueous solution of sorbitol $\left(c_{\text {sorbitol }}=0.05 \mathrm{M}\right)$ with $1.0 \mathrm{~g}$ of $\beta(75)$ and $800 \mathrm{~min}^{-1}$ as the stirring speed with an autogenous pressure for 3 h. Prior to increasing the temperature to $503 \mathrm{~K}$, the air was purged out using 1.0 MPa of $\mathrm{N}_{2}$ three times. The analysis of the reaction products followed the same protocol for the continuous-flow system.

\section{RESULTS AND DISCUSSION}

Catalyst Characterization. The textural properties of all of the used $\beta$ zeolites, i.e., $\beta(12.5), \beta(75)$, and $\beta(150)$, were characterized via $\mathrm{N}_{2}$-sorption, XRD, SEM, and Pyr-IR. The specific surface area $\left(A_{\mathrm{BET}}\right)$, the pore volume $\left(V_{\mathrm{p}}\right)$, and the average pore diameter $\left(D_{\mathrm{p}}\right)$ were deduced from $\mathrm{N}_{2}$ sorption, $c f$. Table S1 in the SI. $\beta(75)$ and $\beta(150)$ exhibited higher specific surface areas of 520 and $451 \mathrm{~m}^{2} \mathrm{~g}^{-1}$ with respect to $\beta(12.5)$, i.e., $111 \mathrm{~m}^{2} \mathrm{~g}^{-1}$. A similar trend was found for specific pore volume, whereas the average pore diameter $\left(D_{\mathrm{p}}\right)$ was in the mesopore range $\left(D_{\mathrm{p}} \sim 5 \mathrm{~nm}\right)$ for all used $\beta$ zeolites, see Table $\mathrm{S} 1$ in the SI. Moreover, the XRD patterns of fresh $\beta$ zeolites used in this work exhibited the typical reflection of zeolites (Figure S6 in the SI). Similarly, the SEM images showed typical zeolite morphology, $c f$. ., Figure S7 in the SI.

The Brønsted (BAS) and Lewis acid site (LAS) densities of the fresh $\beta$ zeolites have been quantified using Pyr-IR at different temperatures, i.e., 423, 523, and $623 \mathrm{~K}$, cf. Table S2 in the SI. At all measured temperatures, the amount of total acid sites decreases with an increase of the $\mathrm{Si} / \mathrm{Al}$ molar ratio of the zeolites. At a temperature of $523 \mathrm{~K}$ (the closest temperature to the reaction temperature, $c f$. next section at the catalytic results), the total acid site densities (BAS and LAS) were 393, 83 , and $54 \mu \mathrm{mol} \mathrm{g}^{-1}$ for $\beta(12.5), \beta(75)$, and $\beta(150)$, respectively. As expected, by increasing the $\mathrm{Si} / \mathrm{Al}$ molar ratio, i.e., $\beta(12,5), \beta(75)$, and $\beta(150)$, the BAS has been found to be decreased in all utilized $\beta$ zeolites at $523 \mathrm{~K} . \beta(75)$ showed a BAS of $69 \mu \mathrm{mol} \mathrm{g}^{-1}$ and a LAS of $14 \mu \mathrm{mol} \mathrm{g}^{-1}$ at $523 \mathrm{~K}$, while $\beta(150)$ possesses a lower BAS of $50 \mu \mathrm{mol} \mathrm{g}^{-1}$ and a LAS of 4 $\mu \mathrm{mol} \mathrm{\textrm {g } ^ { - 1 }}$ at $523 \mathrm{~K}$, with respect to those of $\beta(12.5)$ and $\beta(150)$. To investigate the strength of these acidic sites, Pyr-IR measurements were performed at 423,523 , and $623 \mathrm{~K}$. In all cases, increasing the measurement temperatures is combined with a decrease in BAS or LAS density (Table S2 in the SI). It is worth mentioning that LAS significantly decreased at $\beta(75)$ and $\beta(150)$ by increasing the temperature of Pyr-IR measurements to 10 and $3 \mu \mathrm{mol} \mathrm{g}{ }^{-1}$, respectively. This indicated that BAS was found to be the strong and stable acid sites in these $\beta$ zeolites at elevated measurement temperatures, which show that BAS are the responsible sites of the activity of $\beta$ zeolites in the dehydration of sorbitol to isosorbide at $503 \mathrm{~K}$.

In addition, the silanol group amount in all three $\beta$ zeolites has been deduced from the Fourier transform infrared (FT-IR) measurements. It has been found that silanol groups are directly dependent on the $\mathrm{Si} / \mathrm{Al}$ molar ratio and amounted to 591, 1289, and $2542 \mu \mathrm{mol} \mathrm{g}^{-1}$ for $\beta(12.5), \beta(75)$, and $\beta(150)$, respectively.

The 35 wt $\% \mathrm{Ni}$ on nitrogen-doped carbon (35Ni/NDC) as a catalyst for the hydrogenation of glucose to sorbitol in the integrated process in this work was exactly the same catalyst used in our previous work. ${ }^{11}$ This catalyst (35Ni/NDC) was intensively characterized in our previous work, and thus, we refer to our previous work for the detailed characterization of this catalyst. Furthermore, we have added the results of $\mathrm{N}_{2}$ physisorption and XRD to the SI of this work (Table S1 and Figure S6 in the SI). ${ }^{11}$

Sorbitol Dehydration to Isosorbide. Based on the literature, $\beta$ zeolite was selected as a catalyst for sorbitol dehydration to isosorbide. $\beta$ zeolite has a three-dimensional pore architecture and offers sufficient specific surface area $\left(400-600 \mathrm{~m}^{2} \mathrm{~g}^{-1}\right)$ and total acid site densities $(200-600 \mu \mathrm{mol}$ $\left.\mathrm{g}^{-1}\right)$ to perform efficiently the bimolecular dehydration of sorbitol to isosorbide. In addition, it allows quick diffusion to/ from the pores since its pore size $\left(6.6 \times 6.7 \AA^{2}\right)$ is larger than the cross section of both sorbitol $\left(5.7 \times 5.9 \AA^{2}\right)$ and isosorbide $\left(5.9 \times 6.2 \AA^{2}\right)$. As an attempt to maximize isosorbide yield from an aqueous solution of sorbitol in a flow system, the reaction temperature, acid site density of $\beta$ zeolite, and catalyst contact time were varied.

Initially, $\beta$ zeolite with a $\mathrm{Si} / \mathrm{Al}$ molar ratio of 75 has been selected to perform a temperature study, as it showed optimum catalytic performance in the molten bulk phase. ${ }^{57}$ Therefore, increasing the reaction temperature from 473 to $503 \mathrm{~K}$ was found coupled with a gradual increase of sorbitol conversion from 80 to $95 \mathrm{~mol} \%$ and isosorbide yield from 38 to $83 \mathrm{~mol} \%$ (Figure 1). A lower reaction temperature resulted in the formation of higher amounts of 1,4-sorbitan instead of isosorbide due to an insufficient amount of energy to enable the efficient performance of the second dehydration from 1,4sorbitan to isosorbide (Figure 1). The conversion of sorbitol (95 mol \%) remained constant throughout the further increase of reaction temperature to $523 \mathrm{~K}$. However, isosorbide yield was found to decrease from $83 \mathrm{~mol} \%$ at $503 \mathrm{~K}$ to $76 \mathrm{~mol} \%$ at $513 \mathrm{~K}$ and subsequently to $68 \mathrm{~mol} \%$ at $523 \mathrm{~K}$ without any identified byproducts. This gradual decrease of isosorbide yield 


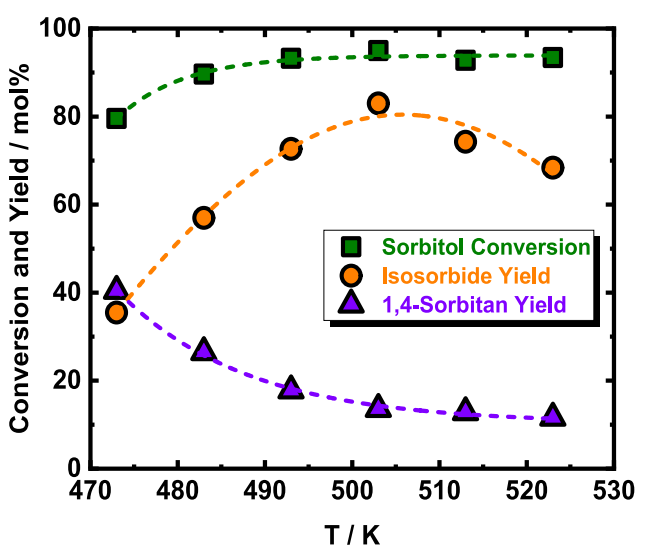

Figure 1. Conversion of sorbitol and the yield of isosorbide and 1,4sorbitan as a function of reaction temperature; reaction conditions: $c_{\text {sorbitol }}=0.05 \mathrm{M} ; Q_{\text {solution }}=0.3 \mathrm{~cm}^{3} \mathrm{~min}^{-1} ; T=473,483,493,503$, 513 , and $523 \mathrm{~K} ; p_{\text {system }}=4.0 \mathrm{MPa} ; m_{\text {catalyst }}=2.5 \mathrm{~g}$; and space time $=$ $3.0 \mathrm{~h} \mathrm{~kg} \mathrm{~mol}{ }^{-1}$.

at temperatures above $503 \mathrm{~K}$ is due to the formation of highly condensed humic species (dark brown colored solution) that also deposit on the catalyst. TGA analysis for the spent catalyst showed a weight loss of around $3.0 \mathrm{wt} \%$, reflecting this deposition. This indicates that isosorbide is not stable at temperatures higher than $503 \mathrm{~K}$. Moreover, the blank experiment with the absence of a catalyst at $503 \mathrm{~K}$ showed no conversion of sorbitol, which is stable under these reaction conditions. This indicates that the presence of a solid acid catalyst is essential to enable the dehydration of sorbitol to isosorbide. Furthermore, these findings indicate the degradation of the products as the major limitation for further temperature increases. In these regards, the removal of products from the hot reaction environment guaranteed by continuous-flow systems can be beneficial for selectively perform the dehydration of sorbitol to isosorbide; i.e., using the continuous-flow system, sorbitol is converted selectivity to 1,4-sorbitan and isosorbide with no additional byproducts such as the isomers of 1,4-sorbitan.

To gain more insight into the reaction kinetics, the apparent activation energy $\left(E_{\mathrm{a}}\right)$ for the first dehydration (sorbitol to 1,4sorbitan) and second dehydration (sorbitol to isosorbide) reactions were calculated from the Arrhenius plot assuming first-order kinetics (Figure S8 in the SI). The calculated values are 55 and $125 \mathrm{~kJ} \mathrm{~mol}^{-1}$, respectively. These calculated $E_{\mathrm{a}}$ values are lower than the one reported in the literature for sorbitol dehydration over heterogeneous catalysts in a moltenphase batch system, i.e., silicotungstic acid $\left(140.3 \mathrm{~kJ} \mathrm{~mol}^{-173}\right)$, sulfonated $\mathrm{ZrO}_{2}\left(87 \mathrm{~kJ} \mathrm{~mol}^{-152}\right)$, and $\beta$ zeolite $(89 \mathrm{~kJ}$ $\left.\mathrm{mol}^{-1}\right){ }^{57}$ Our $55 \mathrm{~kJ} \mathrm{~mol}^{-1}$ for sorbitol dehydration to $1,4-$ sorbitan was comparable to the value calculated of $\beta$ zeolite with a Si/Al molar ratio of 19 and homogenous catalysts (73 and $48 \mathrm{~kJ} \mathrm{~mol}^{-1}$ for $\mathrm{H}_{2} \mathrm{SO}_{4}$ ), respectively. ${ }^{37,38,74}$ In addition, the calculated $E_{\mathrm{a}}$ for 1,4-sorbitan dehydration to isosorbide is comparable to the reported value for $\beta$ zeolite with a $\mathrm{Si} / \mathrm{Al}$ molar ratio of 19 and silicotungstic acid (132.8 and $104.17 \mathrm{~kJ}$ $\left.\mathrm{mol}^{-1}\right)$, respectively. ${ }^{47,74}$ All of these results indicated that the second dehydration of 1,4-sorbitan to isosorbide is the ratedetermining step, while the reaction at the operation conditions was not limited by transport phenomena. Furthermore, the turnover frequency (TOF) for isosorbide production was found to be $0.64 \mathrm{~h}^{-1}$ at $503 \mathrm{~K}$. These results emphasize the advantages of operating this reaction in a continuous-flow system, which will improve the isosorbide formation.

The effect of contact time was also investigated using $\beta(75)$ and $503 \mathrm{~K}$ as reaction conditions. As expected, below $3.0 \mathrm{~h} \mathrm{~kg}$ $\mathrm{mol}^{-1}$, the reaction turns incomplete and sorbitol conversion decreased from 95 to $81 \mathrm{~mol} \%$ (Figure 2), as well as

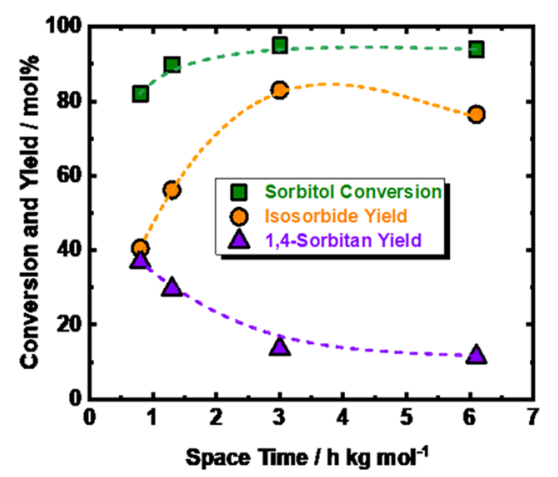

Figure 2. Conversion of sorbitol and the yield of isosorbide and 1,4sorbitan as a function of space time; reaction conditions: $c_{\text {sorbitol }}=0.05$ $\mathrm{M} ; \mathrm{Q}_{\text {solution }}=0.15,0.3 .0 .7,1.0 \mathrm{~cm}^{3} \mathrm{~min}^{-1} ; T=503 \mathrm{~K} ; p_{\text {system }}=4.0$ $\mathrm{MPa} ; m_{\text {catalyst }}=2.5 \mathrm{~g}$; and space time $=6.1,3.0,1.3$, and $0.8 \mathrm{~h} \mathrm{~kg}$ $\mathrm{mol}^{-1}$.

isosorbide yield decreased from 83 to $56 \mathrm{~mol} \%$. Insignificant influence of space time above $3.0 \mathrm{~h} \mathrm{~kg} \mathrm{~mol}^{-1}$ was found on all of the sorbitol conversion and 1,4-sorbitan yields (Figure 2), whereas isosorbide yield slightly decreases from 83 to $76 \mathrm{~mol}$ $\%$. This latter decrease attributed to the longer residence time, which leads to isosorbide decomposition and consequent humification. Accordingly, the use of a flow system allows fast quenching of metastable products to afford high isosorbide yield.

Aiming to fully understand the role of the acid sites in isosorbide production from sorbitol, we investigated $\beta$ zeolites with different $\mathrm{Si} / \mathrm{Al}$ molar ratios $(12.5,75$, and 150) under the optimum reaction conditions. The density and the nature of the active acid sites over the different zeolites were determined by pyridine adsorption and desorption at $523 \mathrm{~K}$, followed by infrared (IR) spectroscopy. The high wavenumber zone of the spectra of the different zeolites after activation (prior to pyridine adsorption) shows a different distribution of the superficial sites (Figures S9 and S10 in the SI). Regardless of the difference in the distribution of the superficial sites, all $\beta$ zeolites showed a sorbitol conversion between 90 and $95 \mathrm{~mol}$ $\%$; however, a difference in the isosorbide yields was observed (Figure 3). $\beta(75)$ with $69 \mu \mathrm{mol} \mathrm{g}^{-1}$ Brønsted acid sites (BAS) showed the maximal isosorbide yield (83 mol \%), while $\beta(12.5)$ with $203 \mu \mathrm{mol} \mathrm{g}^{-1}$ BAS and $\beta(150)$ with $50 \mu \mathrm{mol} \mathrm{g}^{-1}$ BAS only gave isosorbide yields of $\sim 50 \mathrm{~mol} \%$ (Figures 3, S9, and S10). Correspondingly, the 1,4-sorbitan yield was minimized (12 mol \%) using $\beta(75)$. A low Si/Al molar ratio, $\beta(12.5)$, led to =fast dehydration of sorbitol to 1,4 -sorbitan (41 mol \%) but a slow follow-up reaction to isosorbide, leading to the formation of an undesired monodehydration product $(1,4-$ sorbitan) with a yield of $49 \mathrm{~mol} \%$. This observation could be explained by the fact that the removal of water molecules in dehydration reactions in aqueous media is thermodynamically favored by a catalyst with enhanced hydrophobicity, i.e., a high $\mathrm{Si} / \mathrm{Al}$ ratio. ${ }^{57,75,76}$ Next to the number of acid sites, the nature of the superficial sites offering acidity to the material plays an 


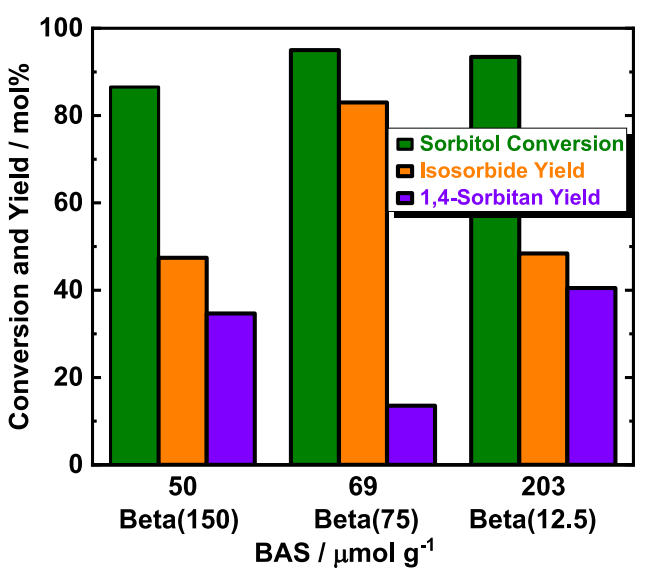

Figure 3. Conversion of sorbitol and the yield of 1,4-sorbitan and isosorbide as a function of Brønsted acid sites at three different $\beta$ zeolites, i.e., $\beta(12.5), \beta(75)$, and $\beta(150)$; reaction conditions: $c_{\text {sorbitol }}=$ $0.05 \mathrm{M}, Q_{\text {solution }}=0.3 \mathrm{~cm}^{3} \mathrm{~min}^{-1}, T=503 \mathrm{~K}, p_{\text {system }}=4.0 \mathrm{MPa}, m_{\text {catalyst }}$ $=2.5 \mathrm{~g}$, and space time $=3.0 \mathrm{~h} \mathrm{~kg} \mathrm{~mol}^{-1}$.

important role in driving the selectivity of the reaction. ${ }^{77}$ Indeed, the presence of terminal $\mathrm{Al}-\mathrm{OH}\left(3780 \mathrm{~cm}^{-1}\right)$ in significant proportions over $\beta(12.5)$ may explain the poor selectivity of the latter, as they were seen to have a certain affinity to pyridine molecules (Figure S9). ${ }^{78,79}$ Over $\beta(75)$, $\mathrm{Al}-\mathrm{OH}$ species are mainly present in the structure in the form of framework $\mathrm{Al}-\mathrm{OH}\left(3602 \mathrm{~cm}^{-1}\right)$, which leads us to believe in their role in the selective production of isosorbide. We should note that excess in the framework $\mathrm{Al}-\mathrm{OH}$ amount may enhance the hydrophilic nature of the material and thus leads to the formation of the undesired monodehydration product (1,4-sorbitan). ${ }^{80}$ A further increase in $\mathrm{Si} / \mathrm{Al}$ molar ratio from 75 to 150 is coupled with a reduction in the amount of BAS together with an increase in the amount of silanol $\mathrm{Si}-\mathrm{OH}$ species. As a result, the use of $\beta(150)$ lowers the isosorbide yield from 83 to $52 \mathrm{~mol} \%$. These results are in strong agreement with the finding of Kobayashi et al. ${ }^{57}$ for the meltphase synthesis in a batch system at $400 \mathrm{~K}$. However, the sorbitol conversion and isosorbide and 1,4-sorbitan yields were found higher over the whole range of $\mathrm{Si} / \mathrm{Al}$ ratio, which we attribute to the higher temperature, i.e., $503 \mathrm{~K}$, as well as the absence of diffusion limitation due to the continuous-flow system usage.

An experiment at low space time, of $0.8 \mathrm{~h} \mathrm{~kg} \mathrm{~mol}^{-1}$ at $503 \mathrm{~K}$, was performed to ensure that isosorbide and 1,4-sorbitan are the only reaction products by operating the reaction wherein the sorbitol conversion was not at its maximum ( $<94 \mathrm{~mol} \%)$, cf., Figure S11 in the SI. After 3.5 h of time on stream (TOS), isosorbide and 1,4-sorbitan were the only detected products with yields of 50 and $40 \mathrm{~mol} \%$, respectively. With the progress of the reaction, the conversion of sorbitol and the yield of isosorbide gradually decrease respectively to 60 and $10 \mathrm{~mol} \%$ after $12 \mathrm{~h}$ of TOS. At this TOS value, 1,4-sorbitan was the dominant product (yield of around $40 \mathrm{~mol} \%$ ). This finding is further evidence that the dehydration of sorbitol in the continuous-flow system resulted in 1,4-sorbitan and isosorbide. Also, it emphasizes that the dehydration of 1,4-sorbitan to isosorbide is the rate-determining step. On the other hand, the gradual drop of sorbitol conversion and isosorbide yield is attributed to the hydrothermal instability of $\beta(75)$ under these harsh reaction conditions (Figures S6 and S11 in the SI). In this term, the hydrothermal stability of the zeolite catalyst represents the central drawback of such catalysts for industrial applications.

To investigate this process on a larger scale and analyze process stability at a higher space time, $\beta(75)$ in the pellet form, reaction conditions of $503 \mathrm{~K}$ and $14.8 \mathrm{~h} \mathrm{~kg} \mathrm{~mol}^{-1}$, and a larger prototype setup were used (the experimental details are shown in the SI). Under these reaction conditions and after reaching the steady state, the conversion of sorbitol (94 mol $\%)$ and the yield of isosorbide ( $83 \mathrm{~mol} \%$ ) were maximized, as shown in Figure 4. Also, using this prototype tubular reactor,

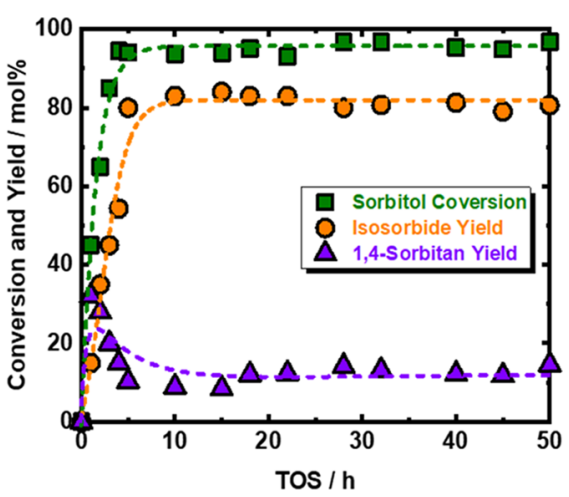

Figure 4. Conversion of sorbitol and the yield of isosorbide and 1,4sorbitan as a function of time on stream (TOS) using $\beta(75)$; reaction conditions: $c_{\text {sorbitol }}=0.05 \mathrm{M}, Q_{\text {solution }}=0.7 \mathrm{~cm}^{3} \mathrm{~min}^{-1}, T=503 \mathrm{~K}$, $p_{\text {system }}=4.0 \mathrm{MPa}, m_{\text {catalyst }}=30 \mathrm{~g}$, and space time $=14.8 \mathrm{~h} \mathrm{~kg} \mathrm{~mol}^{-1}$.

an isosorbide TOF of $0.12 \mathrm{~h}^{-1}$ was calculated. This process was conducted for $50 \mathrm{~h}$ of TOS and the catalysts' performance appeared to be stable. These results clearly showed the advantages of using a continuous-flow system for isosorbide synthesis with respect to a batch system in which the catalyst suffers from rapid deactivation, as continuous removal of the products is absent. Postcharacterization of $\beta(75)$ showed a reduction in the specific surface area from 520 to $290 \mathrm{~m}^{2} \mathrm{~g}^{-1}$ combined with a decrease in crystallinity (Table $S 1$ and Figure S6 in the SI). SEM images of the fresh and spent catalysts showed no differences (Figure S7 in the SI). The changes in the textural properties are both due to the deposition of carbonaceous species and the known instability of zeolites in hot aqueous media (Figures S6, S7, S11, and S12 in the SI) and are in good agreement with previous literature reports. ${ }^{81,82}$

For a comparison purpose and deep understanding of the reaction pathway and product distribution, experiments in the batch system were performed in the absence and presence of $\beta(75)$ at $503 \mathrm{~K}$ (Figure 5). The blank experiment (without catalyst) showed no conversion of sorbitol. This is in an agreement with the one performed in a continuous-flow system, as well as shows that the presence of a solid acid catalyst is essential for this reaction. Interestingly, the presence of $\beta(75)$ led to $92 \mathrm{~mol} \%$ conversion of sorbitol to $42 \mathrm{~mol} \%$ of 1,4-sorbitan as a major product (Figure 5), as well as isosorbide of $18 \mathrm{~mol} \%$, 2,5-mannitan of $10 \mathrm{~mol} \%$, and 1,5anhydro-D-sorbitol of $3 \mathrm{~mol} \%$ (the side product was confirmed using HPLC/MS equipped with a hypercarb column and an evaporative light scattering detector (ELSD)). The low yield of isosorbide is due to the deposition of humification products on the surface of the catalyst, which blocked the accessibility to the active acid side (BAS), as well as the absence of removal of the formed product in comparison to the continuous-flow system. This result clearly shows the advantages of using a 


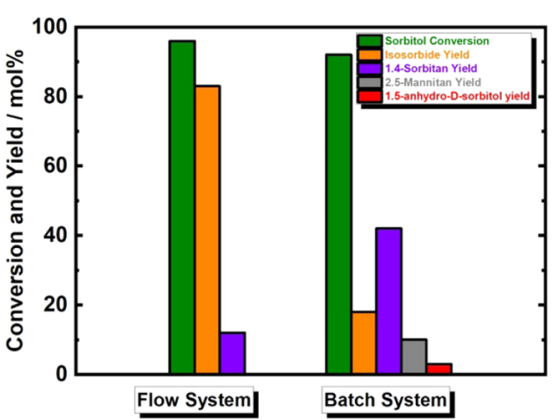

Figure 5. Conversion of sorbitol and isosorbide yield in aqueous liquid-phase dehydration in a continuous-flow reactor and a batch system over $\beta(75)$; reaction conditions in the continuous-flow reactor: $c_{\text {sorbitol }}=0.05 \mathrm{M}, Q_{\text {solution }}=0.3 \mathrm{~cm}^{3} \mathrm{~min}^{-1}, T=503 \mathrm{~K}$, $p_{\text {system }}=4.0 \mathrm{MPa}, m_{\text {catalyst }}=2.5 \mathrm{~g}$ and space time $=3.0 \mathrm{~h} \mathrm{~kg} \mathrm{~mol}^{-1}$; reaction conditions in batch system: $c_{\text {sorbitol }}=0.05 \mathrm{M}, T=503 \mathrm{~K}$, $V_{\text {educt }}=30 \mathrm{~cm}^{3}, m_{\text {catalyst }}=1.0 \mathrm{~g}, n=800 \mathrm{~min}^{-1}, t_{\text {reaction }}=2 \mathrm{~h}$, and autogenous pressure.

continuous-flow system with respect to a batch reactor as it is efficient and leads to high selectivity toward isosorbide.

Integrated Process for Isosorbide Production from Glucose. One of the major advantages of using continuousflow systems consists of straightforward integration for industrial applications. Accordingly, we also explored the integrated process of isosorbide synthesis directly from an aqueous solution of glucose without isolating the in situ formed sorbitol. To perform this experiment, the prototype-scale setup for sorbitol dehydration to isosorbide has been coupled with a similar scale setup for aqueous-phase hydrogenation of glucose to sorbitol using $35 \mathrm{Ni} / \mathrm{NDC}$ catalyst, analogously to what our group has recently reported (the experimental details of the integrated process are described in detail in the SI). In this integrated experiment, the aqueous glucose solution has been fed at the same flow rate, i.e., $0.7 \mathrm{~cm}^{3} \mathrm{~min}^{-1}$, over $35 \mathrm{Ni} / \mathrm{NDC}$ at $423 \mathrm{~K}$ (reactor 1), followed by bimolecular dehydration of the formed sorbitol to isosorbide (reactor 2) on $\beta(75)$ at 503 K. After reaching the steady state, a complete glucose conversion was found (Figure 6). Furthermore, an isosorbide yield of $54 \mathrm{~mol} \%$, together with $14 \mathrm{~mol} \%$ 1,4-sorbitan and 10 mol \% sorbitol that did not undergo dehydration, was calculated (Figure 3). Interestingly, traces of isomannide $(<5$

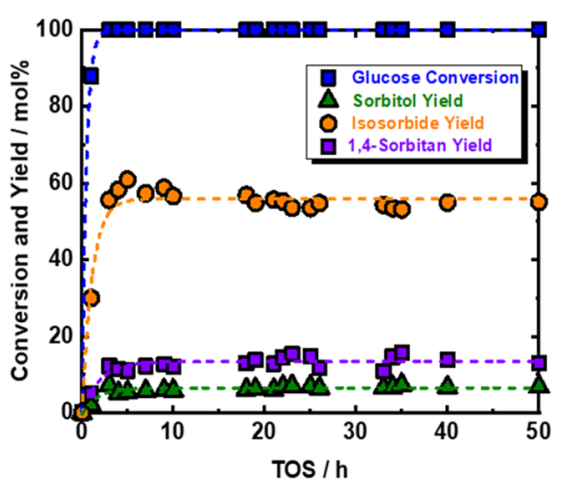

Figure 6. Conversion of glucose and the yields of sorbitol, isosorbide, and 1,4-sorbitan as a function of time on stream (TOS) using $\beta(75)$ and $35 \mathrm{Ni} / \mathrm{NDC}$; reaction conditions: $c_{\text {glucose }}=0.05 \mathrm{M}, Q_{\text {solution }}=0.7$ $\mathrm{cm}^{3} \mathrm{~min}^{-1}, T_{1}=423 \mathrm{~K}$ and $T_{2}=503 \mathrm{~K}, p_{\text {system }}=4.0 \mathrm{MPa}, m_{35 \mathrm{Ni} / \mathrm{NDC}}=$ $10 \mathrm{~g}$ and $m_{\beta(75)}=30 \mathrm{~g}$, and space time $\mathrm{R1:35 \textrm {Ni } / \mathrm { NDC }}=4.9 \mathrm{~h} \mathrm{~kg} \mathrm{~mol}^{-1}$ and $m_{\mathrm{R} 2: \beta(75)}=14.8 \mathrm{~h} \mathrm{~kg} \mathrm{~mol}^{-1}$. mol \%) were observed as a result of hydrogenation of fructose (formed by glucose isomerization) to mannitol followed by dehydration of the intermediates, i.e., mannitol, 2,5-mannitan (Scheme S1 in the SI). These yields of 1,4-sorbitan and isosorbide are comparable to the reported data obtained from the one-pot hydrogenation/dehydration of glucose in water over $\mathrm{Ru}$ /Dowex at $463 \mathrm{~K}$ after $24 \mathrm{~h}$ of reaction time in the batch system. ${ }^{18}$ The performance of the catalysts, i.e., $35 \mathrm{Ni}$ / NDC at glucose hydrogenation and $\beta(75)$ at dehydration of the formed sorbitol to isosorbide, remained constant for $50 \mathrm{~h}$ of TOS. A similar experiment, analyzing only the products after reactor 1, gave a $95 \mathrm{~mol} \%$ conversion of glucose with yields of $88 \mathrm{~mol} \%$ sorbitol and $5 \mathrm{~mol} \%$ fructose (Scheme S1 and Figure S13 in the SI). These findings are in agreement with our previous studies conducted on a smaller scale. ${ }^{11}$ This makes the overall $54 \mathrm{~mol} \%$ isosorbide yield in the integrated experiment up to $78 \mathrm{~mol} \%$ when correlated with the yield of sorbitol that formed from glucose after the first reactor. As expected, the found isosorbide yield is in accordance with the one reported with similar conditions in Section 3.1, i.e., $83 \mathrm{~mol}$ $\%$. This agreement is evidence that isosorbide production from $\beta(75)$ in these conditions is a robust procedure, whose activity is not affected by minor changes in the reactant educts.

\section{CONCLUSIONS}

We reported on the continuous-flow dehydration of sorbitol to isosorbide in liquid water over $\beta$ zeolite, as well as the integrated aqueous-phase glucose hydrogenation to sorbitol, followed by bimolecular dehydration to isosorbide. In both processes, isosorbide was obtained in comparatively high yields. From these observations, a combination of Brønsted acid sites and high specific surface area is a crucial factor to design a highly active catalyst for isosorbide production from sorbitol in the liquid aqueous phase by utilizing a continuousflow system.

The calculated apparent activation energies suggest that the first dehydration step of sorbitol to 1,4-sorbitan is very fast, while the removal of the second water molecule to form isosorbide is the rate-determining step. In this context, the capability of the continuous-flow system to rapidly quench the products has been found beneficial to obtain high isosorbide yields. Moreover, the dehydration toward isosorbide in water was also performed in a medium-sized prototype reactor, which gave efficient and stable performance up to $50 \mathrm{~h}$ of time on stream.

The positive results of this benign process offer a more efficient route for isosorbide production and can make isosorbide an economically feasible replacement for bisphenol-A in polycarbonates and polyesters. Additionally, the proposed integrated process starting from glucose intents to find a replacement for Raney nickel with a safer and more sustainable alternative ( $35 \mathrm{Ni} / \mathrm{NDC})$. The missing hydrothermal stability of standard zeolites in aqueous media at elevated temperatures remains the central drawback for the application of standard zeolites on a larger biorefinery scale. Therefore, the development of new, hydrothermally stable, heterogeneous acid catalysts is eagerly required. Finally, an investigation into this process on a large scale (pilot plant level) should be considered to elucidate the industrial relevance of this approach. 


\section{ASSOCIATED CONTENT}

\section{(s) Supporting Information}

The Supporting Information is available free of charge at https://pubs.acs.org/doi/10.1021/acssuschemeng.0c08167.

(PDF)

\section{AUTHOR INFORMATION}

\section{Corresponding Author}

Majd Al-Naji - Department of Colloids, Max Planck Institute of Colloids and Interface, 14476 Potsdam, Germany; ○ orcid.org/0000-0001-5024-0449; Email: majd.al-naji@ mpikg.mpg.de

\section{Authors}

Francesco Brandi - Department of Colloids, Max Planck Institute of Colloids and Interface, 14476 Potsdam, Germany; 이이.org/0000-0002-6765-6755

Ibrahim Khalil - Centre for Sustainable Catalysis and Engineering, KU Leuven, 3001 Leuven, Belgium

Markus Antonietti - Department of Colloids, Max Planck Institute of Colloids and Interface, 14476 Potsdam, Germany

Complete contact information is available at:

https://pubs.acs.org/10.1021/acssuschemeng.0c08167

\section{Author Contributions}

${ }^{\S}$ F.B. and M.A.-N. contributed equally to this work.

\section{Notes}

The authors declare no competing financial interest.

\section{ACKNOWLEDGMENTS}

The authors are grateful for the financial support from the Max Planck Society. Ibrahim Khalil acknowledges "FWO Vlaanderen" (grant 1260321N) for financial support. Scientific discussions, suggestions, and feedback from Drs. Baris Kumru and Paolo Giusto are gratefully acknowledged. The authors are thankful to Prof. Michiel Dusselier for providing us with the possibility to perform the Pyr-IR measurements and his feedback on the manuscript. Thanks are also extended to Jessica Brandt, Dr. Tobias Hiel, and Antje Völkel from the Max Planck Institute of Colloids and Interfaces for elemental analyses, TEM measurements, and TGA measurements, respectively. Irina Shekova is gratefully acknowledged for the $\mathrm{N}_{2}$ physisorption measurements and technical support. Special thanks to Giulio Fittolani from the department of Biomolecular Systems at Max Planck Institute of Colloids and Interfaces for his effort in HPLC analysis. Klaus Bienert, Michael Born, Marco Bott, and Tobias Schmidt from the electrical and mechanical workshops at the Max Planck Institute of Colloids and Interfaces are greatly acknowledged. The authors are thankful to Valerio Cerasani and Alaa Al-Naji for the idea and design of the graphical abstract and the cover artwork.

\section{REFERENCES}

(1) Liao, Y.; Koelewijn, S.-F.; Van den Bossche, G.; Van Aelst, J.; Van den Bosch, S.; Renders, T.; Navare, K.; Nicolaï, T.; Van Aelst, K.; Maesen, M.; et al. sustainable wood biorefinery for low-carbon footprint chemicals production. Science 2020, 367, 1385-1390.

(2) Hassan, S. S.; Williams, G. A.; Jaiswal, A. K. Moving towards the second generation of lignocellulosic biorefineries in the EU: Drivers, challenges, and opportunities. Renewable Sustainable Energy Rev. 2019, $101,590-599$.
(3) Khalil, I.; Jabraoui, H.; Lebègue, S.; Kim, W. J.; Aguilera, L.-J.; Thomas, K.; Maugé, F.; Badawi, M. Biofuel purification: Coupling experimental and theoretical investigations for efficient separation of phenol from aromatics by zeolites. Chem. Eng. J. 2020, 402, No. 126264.

(4) Isikgor, F. H.; Becer, C. R. Lignocellulosic biomass: A sustainable platform for the production of bio-based chemicals and polymers. Polym. Chem. 2015, 6, 4497-4559.

(5) Mika, L. T.; Cséfalvay, E.; Németh, Á. Catalytic conversion of carbohydrates to initial platform chemicals: Chemistry and sustainability. Chem. Rev. 2018, 118, 505-613.

(6) Esposito, D.; Antonietti, M. Redefining biorefinery: The search for unconventional building blocks for materials. Chem. Soc. Rev. 2015, 44, 5821-5835.

(7) Khalil, I.; Quintens, G.; Junkers, T.; Dusselier, M. Muconic acid isomers as platform chemicals and monomers in the biobased economy. Green Chem. 2020, 22, 1517-1541.

(8) Mendoza Mesa, J. A.; Brandi, F.; Shekova, I.; Antonietti, M.; AlNaji, M. p-xylene from 2,5-dimethylfuran and acrylic acid using zeolite in continuous flow system. Green Chem. 2020, 22, 7398-7405.

(9) Brandi, F.; Bäumel, M.; Shekova, I.; Molinari, V.; Al-Naji, M. 5hydroxymethylfurfural hydrodeoxygenation to 2,5-dimethylfuran in continuous-flow system over $\mathrm{Ni}$ on nitrogen-doped carbon. Sustainable Chem. 2020, 1, 106-115.

(10) Fukuoka, A.; Dhepe, P. L. Catalytic conversion of cellulose into sugar alcohols. Angew. Chem., Int. Ed. 2006, 45, 5161-5163.

(11) Brandi, F.; Bäumel, M.; Molinari, V.; Shekova, I.; Lauermann, I.; Heil, T.; Antonietti, M.; Al-Naji, M. Nickel on nitrogen-doped carbon pellets for continuous-flow hydrogenation of biomass-derived compounds in water. Green Chem. 2020, 22, 2755-2766.

(12) Tamura, M.; Nakagawa, Y.; Tomishige, K. Reduction of sugar derivatives to valuable chemicals: Utilization of asymmetric carbons. Catal. Sci. Technol. 2020, 10, 3805-3824.

(13) Bozell, J. J.; Petersen, G. R. Technology development for the production of biobased products from biorefinery carbohydrates the US Department of Energy's “Top 10” revised. Green Chem. 2010, $12,539-554$.

(14) Delbecq, F.; Khodadadi, M. R.; Rodriguez Padron, D.; Varma, $\mathrm{R}$; Len, C. Isosorbide: Recent advances in catalytic production. Mol. Catal. 2020, 482, No. 110648.

(15) Du, Y.-R.; Xu, B.-H.; Pan, J.-S.; Wu, Y.-W.; Peng, X.-M.; Wang, Y.-F.; Zhang, S.-J. Confinement of brønsted acidic ionic liquids into covalent organic frameworks as a catalyst for dehydrative formation of isosorbide from sorbitol. Green Chem. 2019, 21, 4792-4799.

(16) Yabushita, M. A Study on Catalytic Conversion of Non-food Biomass into Chemicals. Springer Theses, Springer Nature, 2016.

(17) Ochoa-Gómez, J. R.; Roncal, T. Production of Platform Chemicals from Sustainable Resources; Springer, 2017; pp 265-309.

(18) Barbaro, P.; Liguori, F.; Moreno-Marrodan, C. Selective direct conversion of $\mathrm{C} 5$ and $\mathrm{C} 6$ sugars to high added-value chemicals by a bifunctional, single catalytic body. Green Chem. 2016, 18, 2935-2940.

(19) Fenouillot, F.; Rousseau, A.; Colomines, G.; Saint-Loup, R.; Pascault, J. P. Polymers from renewable 1,4:3,6-dianhydrohexitols (isosorbide, isomannide and isoidide): A review. Prog. Polym. Sci. 2010, 35, 578-622.

(20) Herrera-González, A. M.; Pérez-Mondragón, A. A.; CuevasSuárez, C. E. Evaluation of bio-based monomers from isosorbide used in the formulation of dental composite resins. J. Mech. Behav. Biomed. Mater. 2019, 100, No. 103371.

(21) Kasmi, N.; Ainali, N. M.; Agapiou, E.; Papadopoulos, L.; Papageorgiou, G. Z.; Bikiaris, D. N. Novel high tg fully biobased poly(hexamethylene-co-isosorbide-2,5-furan dicarboxylate) copolyesters: Synergistic effect of isosorbide insertion on thermal performance enhancement. Polym. Degrad. Stab. 2019, 169, No. 108983.

(22) Kim, S.-S.; Lau, C. M.; Lillie, L. M.; Tolman, W. B.; Reineke, T. M.; Ellison, C. J. Degradable thermoset fibers from carbohydratederived diols via thiol-ene photopolymerization. ACS Appl. Polym. Mater. 2019, 1, 2933-2942. 
(23) Saxon, D. J.; Luke, A. M.; Sajjad, H.; Tolman, W. B.; Reineke, T. M. Next-generation polymers: Isosorbide as a renewable alternative. Prog. Polym. Sci. 2020, 101, No. 101196.

(24) Saxon, D. J.; Nasiri, M.; Mandal, M.; Maduskar, S.; Dauenhauer, P. J.; Cramer, C. J.; LaPointe, A. M.; Reineke, T. M. Architectural control of isosorbide-based polyethers via ring-opening polymerization. J. Am. Chem. Soc. 2019, 141, 5107-5111.

(25) Yang, W.; Guan, D.; Liu, J.; Luo, Y.; Wang, Y. Synthesis and characterization of biodegradable linear shape memory polyurethanes with high mechanical performance by incorporating novel long chain diisocyanates. New J. Chem. 2020, 44, 3493-3503.

(26) Zia, K. M.; Noreen, A.; Zuber, M.; Tabasum, S.; Mujahid, M. Recent developments and future prospects on bio-based polyesters derived from renewable resources: A review. Int. J. Biol. Macromol. 2016, 82, 1028-1040.

(27) Dussenne, C.; Delaunay, T.; Wiatz, V.; Wyart, H.; Suisse, I.; Sauthier, M. Synthesis of isosorbide: An overview of challenging reactions. Green Chem. 2017, 19, 5332-5344.

(28) Polysorb Registered Product from Roquette, 2019. https:// www.roquette.com/industries/selected-products/industryperformancematerials-isosorbide (accessed Dec 15, 2020).

(29) Mitshubishi Chemical Corporation. News Release: A first in Europe: Mitshubishi Chemical's DURABIO Bio-based Engineering Plastic Adopted for Outer Mask for Speedometer-Tachometer Combo of Renault' s New Clio, 2016. https://www.mchemical.co. jp/en/news/kagaku/pdf/00437/00499.pdf (accessed Dec 15, 2020).

(30) Teijin Company. News Release: Teijin Develops Formable Gsoline-Resistant Bioplastic Film for Vehicle Door Handles Integrated with Smart-Entry Systems, 2018. https://www.teijin. $\mathrm{com} /$ products/resin/planext/pdf/planext_related_01.pdf (accessed Dec 15, 2020).

(31) Lai, W.; Wu, G. Reactive blending of bisphenol-a polycarbonate with isosorbide-based polycarbonates: Effect of chain flexibility and compatibility. React. Funct. Polym. 2019, 143, No. 104328.

(32) Ouyang, Q.; Liu, J.; Li, C.; Zheng, L.; Xiao, Y.; Wu, S.; Zhang, B. A facile method to synthesize bio-based and biodegradable copolymers from furandicarboxylic acid and isosorbide with high molecular weights and excellent thermal and mechanical properties. Polym. Chem. 2019, 10, 5594-5601.

(33) Russo, F.; Galiano, F.; Pedace, F.; Aricò, F.; Figoli, A. Dimethyl isosorbide as a green solvent for sustainable ultrafiltration and microfiltration membrane preparation. ACS Sustainable Chem. Eng. 2020, 8, 659-668.

(34) Cohn, J. N.; Johnson, G.; Ziesche, S.; Cobb, F.; Francis, G.; Tristani, F.; Smith, R.; Dunkman, W. B.; Loeb, H.; Wong, M.; et al. A comparison of enalapril with hydralazine-isosorbide dinitrate in the treatment of chronic congestive heart failure. N. Engl. J. Med. 1991, $325,303-310$.

(35) NIH. Livertox: Clinical and Research Information on DrugInduced Liver Injury; National Institute of Diabetes and Digestive and Kidney Diseases, 2017. https://livertox.nih.gov.

(36) Lichtenthaler, F. W. Carbohydrates: Occurrence, Structures and Chemistry. Ullmann's Encyclopedia of Industrial Chemistry; WileyVCH Verlag GmbH \& Co. KGaA: Weinheim, 2010; pp 617-646.

(37) Kamm, B.; Gruber, P. R.; Kamm, M. Biorefineries-Industrial Processes and Products. Ullmans Encyclopedia of Industrial Chemistry; Wiley-VCH Verlag GmbH \& Co. KgaA: Weinheim, 2015; pp 1-32.

(38) Schiweck, H.; Roland Vogel, A. B.; Schwarz, E.; Kunz, M.; Dusdutois, C.; Clement, A.; Lefranc, C.; Lüssem, B.; Moser, M.; Peters, S. Sugar Alcohols. Ullman's Encyclopedia of Industrial Chemistry; Wiley-VCH Verlag GmbH \& Co. KGaA: Weinheim, 2012; pp 1-32.

(39) Sheldon, R. A. Green and sustainable manufacture of chemicals from biomass: State of the art. Green Chem. 2014, 16, 950-963.

(40) Sheldon, R. A. Green solvents for sustainable organic synthesis: State of the art. Green Chem. 2005, 7, 267-278.

(41) Ahmed, I.; Khan, N. A.; Mishra, D. K.; Lee, J. S.; Hwang, J.-S.; Jhung, S. H. Liquid-phase dehydration of sorbitol to isosorbide using sulfated titania as a solid acid catalyst. Chem. Eng. Sci. 2013, 93, 9195.

(42) Zou, J.; Cao, D.; Tao, W.; Zhang, S.; Cui, L.; Zeng, F.; Cai, W. Sorbitol dehydration into isosorbide over a cellulose-derived solid acid catalyst. RSC Adv. 2016, 6, 49528-49536.

(43) Cao, D.; Yu, B.; Zhang, S.; Cui, L.; Zhang, J.; Cai, W. Isosorbide production from sorbitol over porous zirconium phosphate catalyst. Appl. Catal., A 2016, 528, 59-66.

(44) Cubo, A.; Iglesias, J.; Morales, G.; Melero, J. A.; Moreno, J.; Sánchez-Vázquez, R. Dehydration of sorbitol to isosorbide in melted phase with propyl-sulfonic functionalized sba-15: Influence of catalyst hydrophobization. Appl. Catal., A 2017, 531, 151-160.

(45) Ginés-Molina, M. J.; Moreno-Tost, R.; Santamaría-González, J.; Maireles-Torres, P. Dehydration of sorbitol to isosorbide over sulfonic acid resins under solvent-free conditions. Appl. Catal., A 2017, 537, $66-73$.

(46) Jeong, S.; Jeon, K.-J.; Park, Y.-K.; Kim, B.-J.; Chung, K.-H.; Jung, S.-C. Catalytic properties of microporous zeolite catalysts in synthesis of isosorbide from sorbitol by dehydration. Catalysts 2020, 10, No. 148.

(47) Kamaruzaman, M. R.; Jiang, X. X.; Hu, X. D.; Chin, S. Y. High yield of isosorbide production from sorbitol dehydration catalysed by amberlyst 36 under mild condition. Chem. Eng. J. 2020, 388, No. 124186.

(48) Li, J.; Spina, A.; Moulijn, J. A.; Makkee, M. Sorbitol dehydration into isosorbide in a molten salt hydrate medium. Catal. Sci. Technol. 2013, 3, 1540-1546.

(49) Polaert, I.; Felix, M. C.; Fornasero, M.; Marcotte, S.; Buvat, J.C.; Estel, L. A greener process for isosorbide production: Kinetic study of the catalytic dehydration of pure sorbitol under microwave. Chem. Eng. J. 2013, 222, 228-239.

(50) Sun, P.; Yu, D. H.; Hu, Y.; Tang, Z. C.; Xia, J. J.; Li, H.; Huang, H. $\mathrm{H}_{3} \mathrm{PW}_{12} \mathrm{O}_{40} / \mathrm{SiO}_{2}$ for sorbitol dehydration to isosorbide: High efficient and reusable solid acid catalyst. Korean J. Chem. Eng. 2011, 28, 99-105.

(51) Yuan, D.; Li, L.; Li, F.; Wang, Y.; Wang, F.; Zhao, N.; Xiao, F. Solvent-free production of isosorbide from sorbitol catalyzed by a polymeric solid acid. ChemSusChem 2019, 12, 4986-4995.

(52) Zhang, X.; Rabee, A. I. M.; Isaacs, M.; Lee, A. F.; Wilson, K. Sulfated zirconia catalysts for D-sorbitol cascade cyclodehydration to isosorbide: Impact of zirconia phase. ACS Sustainable Chem. Eng. 2018, 6, 14704-14712.

(53) Zhang, Y.; Chen, T.; Zhang, G.; Wang, G.; Zhang, H. Efficient production of isosorbide from sorbitol dehydration over mesoporous carbon-based acid catalyst. Appl. Catal., A 2019, 575, 38-47.

(54) Dabbawala, A. A.; Mishra, D. K.; Huber, G. W.; Hwang, J.-S. Role of acid sites and selectivity correlation in solvent free liquid phase dehydration of sorbitol to isosorbide. Appl. Catal., A 2015, 492, $252-261$.

(55) Zhang, Y.; Chen, T.; Zhang, G.; Wang, G.; Zhang, H. Mesoporsous Al-promotes sulfated zirconia as efficient heterogeneous catalyst to synthesize isosorbide from sorbitol. Appl. Catal., A 2018, $562,258-266$

(56) Deng, J.; Xu, B.-H.; Wang, Y.-F.; Mo, X.-E.; Zhang, R.; Li, Y.; Zhang, S.-J. Brønsted acidic ionic liquid-catalyzed dehydrative formation of isosorbide from sorbitol: introduction of a continuous process. Catal. Sci. Technol. 2017, 7, 2065-2073.

(57) Kobayashi, H.; Yokoyama, H.; Feng, B.; Fukuoka, A. Dehydration of sorbitol to isosorbide over h-beta zeolites with high si/al ratios. Green Chem. 2015, 17, 2732-2735.

(58) Otomo, R.; Yokoi, T.; Tatsumi, T. Synthesis of isosorbide from sorbitol in water over high-silica aluminosilicate zeolites. Appl. Catal., A 2015, 505, 28-35.

(59) Yamaguchi, A.; Hiyoshi, N.; Sato, O.; Shirai, M. Sorbitol dehydration in high temperature liquid water. Green Chem. 2011, 13, $873-881$.

(60) Op de Beeck, B.; Geboers, J.; Van de Vyver, S.; Van Lishout, J.; Snelders, J.; Huijgen, W. J.; Courtin, C. M.; Jacobs, P. A.; Sels, B. F. 
Conversion of (ligno)cellulose feeds to isosorbide with heteropoly acids and $\mathrm{Ru}$ on carbon. ChemSusChem 2013, 6, 199-208.

(61) Plutschack, M. B.; Pieber, B.; Gilmore, K.; Seeberger, P. H. The hitchhiker's guide to flow chemistry parallel. Chem. Rev. 2017, 117, 11796-11893.

(62) Gérardy, R.; Emmanuel, N.; Toupy, T.; Kassin, V.-E.; Tshibalonza, N. N.; Schmitz, M.; Monbaliu, J.-C. M. Continuous flow organic chemistry: Successes and pitfalls at the interface with current societal challenges. Eur. J. Org. Chem. 2018, 2018, 23012351.

(63) Gutmann, B.; Kappe, C. O. Forbidden chemistries - paths to a sustainable future engaging continuous processing. J. Flow Chem. $2017,7,65-71$.

(64) Braun, M.; Antonietti, M. A continuous flow process for the production of 2, 5-dimethylfuran from fructose using (non-noble metal based) heterogeneous catalysis. Green Chem. 2017, 19, 38133819.

(65) Gérardy, R.; Morodo, R.; Estager, J.; Luis, P.; Debecker, D. P.; Monbaliu, J.-C. M. Sustaining the transition from a petrobased to a biobased chemical industry with flow chemistry. Top. Curr. Chem. 2019, 377, No. 1.

(66) Hommes, A.; Heeres, H. J.; Yue, J. Catalytic transformation of biomass derivatives to value-added chemicals and fuels in continuous flow microreactors. Chem CatChem 2019, 11, 4671-4708.

(67) Gérardy, R.; Debecker, D. P.; Estager, J.; Luis, P.; Monbaliu, J. M. Continuous flow upgrading of selected c2-c6 platform chemicals derived from biomass. Chem. Rev. 2020, 120, 7219-7347.

(68) Gu, M.; Yu, D.; Zhang, H.; Sun, P.; Huang, H. Metal (IV) phosphates as solid catalysts for selective dehydration of sorbitol to isosorbide. Catal. Lett. 2009, 133, 214-220.

(69) Xia, J.; Yu, D.; Hu, Y.; Zou, B.; Sun, P.; Li, H.; Huang, H. Sulfated copper oxide: An efficient catalyst for dehydration of sorbitol to isosorbide. Catal. Commun. 2011, 12, 544-547.

(70) Zhang, X.; Yu, D.; Zhao, J.; Zhang, W.; Dong, Y.; Huang, H. The effect of $\mathrm{P} / \mathrm{Ta}$ ratio on sorbitol dehydration over modified tantalum oxide by phosphoric acid. Catal. Commun. 2014, 43, 29-33.

(71) Xi, J.; Zhang, Y.; Ding, D.; Xia, Q.; Wang, J.; Liu, X.; Lu, G.; Wang, Y. Catalytic production of isosorbide from cellulose over mesoporous niobium phosphate-based heterogeneous catalysts via a sequential process. Appl. Catal., A 2014, 469, 108-115.

(72) Al-Naji, M.; Puertolas, B.; Kumru, B.; Cruz, D.; Baumel, M.; Schmidt, B.; Tarakina, N. V.; Perez-Ramirez, J. Sustainable continuous flow valorization of $\gamma$-valerolactone with trioxane to $\alpha$ methylene- $\gamma$-valerolactone over basic beta zeolites. ChemSusChem 2019, 12, 2628-2636.

(73) Oltmanns, J. U.; Palkovits, S.; Palkovits, R. Kinetic investigation of sorbitol and xylitol dehydration catalyzed by silicotungstic acid in water. Appl. Catal., A 2013, 456, 168-173.

(74) Morales, G.; Iglesias, J.; Melero, J. A.; Moreno, J.; SánchezVázquez, R.; Peral, Á.; Cubo, A. Isosorbide production from sorbito over heterogeneous acid catalysts: screening and kinteic study. Top. Catal. 2017, 60, 1027-1039.

(75) Namba, S.; Hosonuma, N.; Yashima, T. Catalytic application for hydrophopic properties of high silica zeolite. J. Catal. 1981, 72, 16-20.

(76) Zhang, J.; Wang, L.; Liu, F.; Meng, X.; Mao, J.; Xiao, F.-S. Enhanced catalytic performance in dehydration of sorbitol to isosorbide over a superhydrophobic mesoporous acid catalyst. Catal. Today 2015, 242, 249-254.

(77) Khalil, I.; Thomas, K.; Jabraoui, H.; Bazin, P.; Maugé, F. Selective elimination of phenol from hydrocarbons by zeolites and silica-based adsorbents-impact of the textural and acidic properties. J. Hazard. Mater. 2020, 384, No. 121397.

(78) Khalil, I.; Celis-Cornejo, C. M.; Thomas, K.; Bazin, P.; Travert, A.; Pérez-Martínez, D. J.; Baldovino-Medrano, V. G.; Paul, J. F.; Maugé, F. In situ IR-ATR study of the interaction of nitrogen heteroaromatic compounds with hy zeolites: Experimental and theoretical approaches. ChemCatChem 2020, 12, 1095-1108.
(79) Palčić, A.; Ordomsky, V. V.; Qin, Z.; Georgieva, V.; Valtchev, V. Tuning zeolite properties for a highly efficient synthesis of propylene from methanol. Chem. - Eur. J. 2018, 24, 13136-13149.

(80) Jabraoui, H.; Khalil, I.; Lebègue, S.; Badawi, M. Ab initio screening of cation-exchanged zeolites for biofuel purification. Mol. Syst. Des. Eng. 2019, 4, 882-892.

(81) Al-Naji, M.; Van Aelst, J.; Liao, Y.; d'Hullian, M.; Tian, Z.; Wang, C.; Gläser, R.; Sels, B. F. Pentanoic acid from $\gamma$-valerolactone and formic acid using bifunctional catalysis. Green Chem. 2020, 22, $1171-1181$

(82) Zhang, L.; Chen, K.; Chen, B.; White, J. L.; Resasco, D. E. Factors that determine zeolite stability in hot liquid water. J. Am. Chem. Soc. 2015, 137, 11810-11819. 